\title{
Patients' Willingness to Take Multiple-Tablet Antiretroviral Therapy Regimens for Treatment of HIV
}

\author{
Esther A. N. Engelhard ${ }^{1,2}$ - Colette Smit ${ }^{2}$ - Sigrid C. J. M. Vervoort ${ }^{3}$ • \\ Peter J. Smit ${ }^{4}$ Pythia T. Nieuwkerk ${ }^{5}$. Frank P. Kroon ${ }^{6}$ Peter Reiss ${ }^{1,2,7,8}$. \\ Kees Brinkman' ${ }^{9}$ Suzanne E. Geerlings ${ }^{1}$
}

Published online: 2 May 2016

(c) The Author(s) 2016. This article is published with open access at Springerlink.com

\begin{abstract}
Background The costs of combination antiretroviral therapy (cART) for HIV, consisting of separate, particularly generic, components (multiple-tablet regimens, MTR) are generally much lower than those of single-tablet regimens (STR) comprising the same active ingredients.
\end{abstract}

On behalf of the ATHENA observational cohort and the Q-HIV study group members listed in the Acknowledgments section.

Esther A. N. Engelhard

eaengelhard@outlook.com

1 Division of Infectious Diseases, Academic Medical Center of the University of Amsterdam, Amsterdam, The Netherlands

2 Stichting HIV Monitoring, Amsterdam, The Netherlands

3 Department of Internal Medicine and Infectious Diseases, University Medical Centre Utrecht, Utrecht, The Netherlands

4 HIV Vereniging Nederland (Dutch HIV Association), Amsterdam, The Netherlands

5 Department of Medical Psychology, Academic Medical Center of the University of Amsterdam, Amsterdam, The Netherlands

6 Department of Infectious Diseases, Leiden University Medical Center, Leiden, The Netherlands

7 Department of Global Health, Academic Medical Center of the University of Amsterdam, Amsterdam, The Netherlands

8 Amsterdam Institute for Global Health and Development, Amsterdam, The Netherlands

9 Department of Internal Medicine, Onze Lieve Vrouwe Gasthuis, Amsterdam, The Netherlands
Objectives To assess whether patients would be willing to take MTR, once-daily, instead of STR, with the goal of reducing general healthcare costs. In addition, we aimed to examine whether willingness was associated with particular patient characteristics.

Methods Data from the ATHENA cohort database in The Netherlands of adult HIV-1-infected patients in care and taking cART $\geq 6$ months were used to select 1000 potential participants for an online patient survey on patient preferences and satisfaction. Participants were asked whether they would be willing to take three pills with the equivalent active ingredients simultaneously instead of STR to reduce costs. Multivariate logistic regression was used to examine associations between patient characteristics and willingness to take MTR instead of STR.

Results Forty-seven percent $(n=152)$ of the 322 respondents answered 'yes' and $26 \% \quad(n=83)$ answered 'maybe' when asked whether they would be willing to take three pills with the equivalent active ingredients simultaneously to reduce costs. Non-Dutch patients were significantly more likely to answer 'no' (OR: 2.49; $95 \%$ CI: 1.17-5.30) or 'maybe' (OR: 2.63; $95 \%$ CI: 1.24-5.60). Answering 'no' was less common among patients who had been taking cART $\geq 15$ years (OR: 0.23 ; $95 \%$ CI: 0.09-0.58). Commonly reported concerns included the dosing frequency, efficacy and tolerability of MTR.

Conclusions HIV-infected patients do not necessarily oppose the decision to prescribe MTR instead of STR to reduce healthcare costs. However, the potential trade-off in terms of convenience should be carefully weighed against the projected savings. 


\section{Key Points}

With the growing availability of generic antiretroviral agents for HIV, switching from singletablet regimens to multiple-tablet regimens is widely considered to be a strategy to reduce healthcare costs. Patients' attitudes towards this issue have not been assessed.

Our study shows that HIV-infected patients in The Netherlands do not necessarily oppose the decision to switch to multiple-tablet regimens for economic reasons. Region of origin and duration of combination antiretroviral therapy (cART) usage may play a role in patients' opinions on this matter.

Common concerns included dosing frequency, efficacy and tolerability of multiple-tablet regimens, and should be carefully addressed in both decision making and in informing the patient.

\section{Introduction}

The development of combination antiretroviral therapy (cART) has led to remarkable improvements in life expectancy and quality of life for those infected with human immunodeficiency virus (HIV) [1]. Not only are cART regimens increasingly potent, they have also been greatly simplified. Regimens have evolved from combinations involving more than 20 pills taken several times per day to co-formulated drugs, taken once or twice daily [2]. Currently, the use of single-tablet regimens (STR), in which all components of a cART regimen are combined into a single tablet administered once daily, is widely recommended as first-line therapy [3].

In contrast to these developments, there has been a recent shift towards the use of non-co-formulated cART generics in the form of multiple-tablet regimens (MTR). These MTR are less expensive than branded STR combinations. In a pharmacoeconomic analysis, Walensky et al. [4] demonstrated that a switch from STR (efavirenzemtricitabine-tenofovir) to MTR (generic efavirenz, generic lamivudine and tenofovir) in the USA would save nearly US\$1 billion in the first year. Another study in the UK showed that switching all patients to available generics could save an estimated $£ 1.1$ billion in 5 years [5].

While the range of available generics, and therefore the options for saving costs through MTR, is expanding, it is unclear to what extent switching to MTR would affect adherence and virological outcomes [6]. Despite the considerable amount of evidence supporting the positive impact of a lower pill burden (number of pills) and dosing frequency on adherence [7-9], few clinical data support the superior effectiveness of STR versus its separate components [3]. Indeed, there is evidence suggesting that STR and once-daily MTR are equally effective [10]. In recent studies evaluating the impact of cost-saving policies, switching to MTR did not affect clinical outcomes [3, 11, 12]. Additional studies supporting equivalence of STR and MTR include a meta-analysis of 19 RCTs [13] and a prospective cohort study [14] in which a lower pill burden in once-daily regimens did not predict better adherence.

The above-mentioned studies have provided evidence of cost savings and equivalent efficacy, but have not evaluated patients' attitudes towards taking MTR. Therefore, we assessed whether patients in The Netherlands would be willing to take MTR, once daily, instead of STR with the goal of reducing costs. In addition, we aimed to identify patient characteristics potentially associated with willingness to take MTR.

\section{Methods}

\subsection{Study Population}

In The Netherlands, all HIV-infected patients are treated in designated HIV treatment centres, and prospectively monitored in the "AIDS therapy evaluation in The Netherlands' (ATHENA) cohort (maintained by Stichting HIV Monitoring, SHM) [15]. We selected 1,000 HIV-1infected patients from all treatment centres for participation in a larger study (Q-HIV) in which we assessed patients' health-related quality of life and perspectives on outpatient HIV care. The treatment centre size was taken into account, ensuring a minimum of 20 potential participants per treatment centre. We selected chronically infected patients with: (1) time since initiation of cART $\geq 6$ months; and (2) age $\geq 18$ years at the time of diagnosis. For the selection, we used the anonymized study ID number assigned to each HIV patient in care by SHM.

Selected potential participants were provided with an information letter and a password for accessing an online questionnaire in Dutch or English. We also offered a paper version of the questionnaire. The study was exempted from written informed consent (by the Medical Ethics Review Committee of the Academic Medical Centre of the University of Amsterdam); we considered consent implicit when a questionnaire was returned to us.

\subsection{Outcome Measures}

The participants were asked as follows whether they would be willing to take an MTR (once daily) instead of an STR to reduce costs: 
"The costs of medication are being critically assessed worldwide. The costs of 3 separate pills are generally much lower than the cost of a combination drug with the same active ingredients. Would you be willing to take 3 pills at the same time instead of 1 pill?

Respondents could answer 'yes', 'no' or 'maybe'. In addition, patients were given the opportunity to comment on the matter ("Please fill in your comment here:..."). We assessed the comments per group ('yes', 'no' or 'maybe').

\subsection{Patient Characteristics}

We used the ATHENA cohort database to extract the patient characteristics of age, sex, region of origin, socioeconomic status (SES), route of HIV transmission, time since cART initiation and time since diagnosis.

Region of origin was based on the country of birth and grouped into The Netherlands, Sub-Saharan Africa (SSA) and 'other'. For the SES we used a classification system previously described by The Netherlands Institute for Social Research [16]. Here, the five classes, based on area codes, were recoded as high, middle or low. Route of transmission was categorized as men who have sex with men (MSM), heterosexual contact or 'other/unknown'.

\subsection{Statistical Analysis}

We used $t$ tests, Mann-Whitney $U$ tests and $\chi^{2}$ analysis to test for differences in characteristics between respondents and non-respondents. Then, we stratified the proportions of respondents answering 'yes', 'no' or 'maybe' according to characteristics, and used $\chi^{2}$ analysis to determine statistically significant differences in proportions between groups.

Using multinomial logistic regression, we assessed potential associations between patient characteristics and answering the question with 'yes', 'no' or 'maybe'. In this analysis, which accommodates three outcomes, we estimated the odds of answering 'no' versus 'yes' and the odds of answering 'maybe' versus 'yes'. We recoded region of origin as either from The Netherlands (Dutch) or 'other' (non-Dutch), and combined sex and transmission route (MSM, heterosexual male, heterosexual female and 'other'). Variables with $p$ values $<0.1$ in the univariate analysis were entered in a multivariate model. All analyses were performed with STATA (version 13).

\section{Results}

Of the 1000 selected patients, 958 patients were eligible for participation (i.e. had not recently died, migrated or switched to another treatment centre). A total of 331 patients from all HIV-treatment centres in The Netherlands completed the questionnaire (response rate: $35 \%$ ) and 322 answered the question regarding switching to MTR. Twenty-five percent of respondents chose to complete the paper version of the questionnaire.

The proportions of males $(85 \%)$, patients originating from The Netherlands (77\%) and MSM (71\%) were significantly higher among respondents than among nonrespondents (73, 50 and $48 \%$, respectively). Respondents were significantly older than non-respondents (average of 51 vs. 47 years) and had a higher SES. The groups did not differ with regard to duration of HIV-infection or time since cART initiation. Of the 322 respondents, $47 \%$ $(n=152)$ answered 'yes', $27 \%(n=87)$ answered 'no' and $26 \%(n=83)$ answered 'maybe' when asked whether they would be willing to use an MTR to reduce costs. Table 1 shows the proportions of respondents answering this question with 'yes', 'no' or 'maybe' according to patient characteristics. An affirmative answer was relatively more common among older patients, men, Dutch patients, MSM and patients with a time since diagnosis or cART initiation of $\geq 15$ years. Female respondents and respondents from SSA were most likely to answer the question with 'maybe'. Finally, patients taking MTR were more likely to answer the question with 'yes'.

\subsection{Respondents Answering 'Yes', 'No' or 'Maybe'}

Table 2 shows the odds of respondents answering 'no' versus 'yes' and 'maybe' versus 'yes'. In the multivariate analyses, non-Dutch patients were significantly more likely to answer 'no' (OR: 2.49; $95 \%$ CI: 1.17-5.30) or 'maybe' (OR: 2.63; $95 \%$ CI: 1.24-5.60). Answering the question with 'no' was less common among patients who had been taking cART $\geq 15$ years (OR: 0.23; 95 \% CI: 0.09-0.58).

\subsection{Views and Concerns}

A total of 105 patients expressed their views in the comment field. Respondents reported that they would consider switching to MTR a step backwards $(n=24)$ and emphasized the importance of taking the pills once daily $(n=6)$. Four patients felt that the high STR prices were driven by the pharmaceutical industry and indicated that pricing is a political matter.

Respondents who answered 'maybe' pointed out that potency and tolerability of the regimen should not be inferior to STR ( $n=5$ ). Having to pay for medication was reported as a reason to consider switching to an MTR $(n=3)$. The most common view of respondents who answered 'no' was that STR are more convenient, particularly when travelling or at work $(n=8)$. Other reasons for reluctance included difficulties swallowing pills $(n=4)$, increased risk of dosage errors $(n=3)$, concerns 
Table 1 Characteristics of respondents answering 'yes', 'no' or 'maybe' to the question whether they would be willing to switch from a single-drug regimen to multiple pills (once daily) for the treatment of HIV

\begin{tabular}{|c|c|c|c|c|}
\hline Characteristic & $\begin{array}{l}\text { Yes } \\
n=152(47 \%)\end{array}$ & $\begin{array}{l}\text { No } \\
n=87(27 \%)\end{array}$ & $\begin{array}{l}\text { Maybe } \\
n=83(26 \%)\end{array}$ & $p$ value \\
\hline \multicolumn{5}{|l|}{ Age (years) } \\
\hline$<40$ & $19(37 \%)$ & $21(41 \%)$ & $11(22 \%)$ & \multirow[t]{4}{*}{0.046} \\
\hline $40-50$ & $43(43 \%)$ & $32(31 \%)$ & $27(26 \%)$ & \\
\hline $50-60$ & $53(53 \%)$ & $17(17 \%)$ & $30(30 \%)$ & \\
\hline$>60$ & $37(54 \%)$ & $17(24 \%)$ & $15(22 \%)$ & \\
\hline \multicolumn{5}{|l|}{ Sex } \\
\hline Male & $139(50 \%)$ & $73(27 \%)$ & $64(23 \%)$ & \multirow[t]{2}{*}{0.009} \\
\hline Female & $13(28 \%)$ & $14(31 \%)$ & $19(41 \%)$ & \\
\hline \multicolumn{5}{|l|}{ Region of origin } \\
\hline The Netherlands & $133(53 \%)$ & $61(24 \%)$ & $58(23 \%)$ & \multirow[t]{3}{*}{$<0.001$} \\
\hline Sub-Saharan Africa & $1(4 \%)$ & $9(38 \%)$ & $14(58 \%)$ & \\
\hline Other & $18(39 \%)$ & $17(37 \%)$ & $11(24 \%)$ & \\
\hline \multicolumn{5}{|l|}{ Socioeconomic status } \\
\hline High & $47(52 \%)$ & $22(24 \%)$ & $22(24 \%)$ & \multirow[t]{4}{*}{0.087} \\
\hline Middle & $56(51 \%)$ & $23(20 \%)$ & $32(29 \%)$ & \\
\hline Low & $46(41 \%)$ & $41(37 \%)$ & $25(22 \%)$ & \\
\hline Missing $^{\mathrm{a}}$ & $3(38 \%)$ & $1(12 \%)$ & $4(50 \%)$ & \\
\hline \multicolumn{5}{|c|}{ Route of HIV transmission } \\
\hline MSM & $123(53 \%)$ & $58(25 \%)$ & $52(22 \%)$ & \multirow[t]{3}{*}{$\mathbf{0 . 0 2 7}$} \\
\hline Heterosexual & $24(33 \%)$ & $24(33 \%)$ & $25(34 \%)$ & \\
\hline Other/unknown & $5(30 \%)$ & $5(35 \%)$ & $6(35 \%)$ & \\
\hline \multicolumn{5}{|c|}{ Time since cART initiation (years) } \\
\hline$<5$ & $32 \mathrm{c}(40 \%)$ & $29(36 \%)$ & $19(24 \%)$ & \multirow[t]{4}{*}{0.002} \\
\hline $5-10$ & $46(47 \%)$ & $28(29 \%)$ & $23(24 \%)$ & \\
\hline $10-15$ & $25(35 \%)$ & $20(28 \%)$ & $26(37 \%)$ & \\
\hline$>15$ & $49(67 \%)$ & $10(13 \%)$ & $15(20 \%)$ & \\
\hline \multicolumn{5}{|c|}{ Time since diagnosis (years) } \\
\hline$<5$ & $17(45 \%)$ & $10(26 \%)$ & $11(29 \%)$ & \multirow[t]{4}{*}{0.012} \\
\hline $5-10$ & $46(43 \%)$ & $38(36 \%)$ & $23(21 \%)$ & \\
\hline $10-15$ & $34(39 \%)$ & $26(29 \%)$ & $28(32 \%)$ & \\
\hline$>15$ & $55(62 \%)$ & $13(15 \%)$ & $21(23 \%)$ & \\
\hline \multicolumn{5}{|l|}{ Currently on STR } \\
\hline No & $134(59 \%)$ & $35(15 \%)$ & $59(26 \%)$ & \multirow[t]{2}{*}{$<0.001$} \\
\hline Yes & $18(19 \%)$ & $52(55 \%)$ & $24(26 \%)$ & \\
\hline
\end{tabular}

$p$ values for the comparison of characteristics ( $\chi^{2}$ analysis)

Bold denotes significant $p$ value $(<0.05)$

cART combination antiretroviral therapy, MSM men who have sex with men, STR single-tablet regimen

a 'Missing' group not included in analysis about perceiving oneself as more ill $(n=3)$ and concerns about side effects $(n=2)$.

\section{Discussion}

With the growing availability of generic antiretroviral agents, switching from STR to MTR is widely being considered as a strategy to reduce healthcare costs. In some settings, this switch has been structurally implemented $[3,11,12]$. The decision to take this measure, which is intuitively paradoxical to the simplification of cART regimens, must be preceded by an assessment of the efficacy of STR versus MTR, estimated savings and patient preferences.

Our study suggests that a considerable proportion of HIV-infected patients in The Netherlands would consider switching to MTR for economic reasons. Almost half the respondents answered 'yes' and a quarter answered 'maybe' when asked whether they would be willing to take 
Table 2 Univariate and multivariate multinomial logistic regression analysis for respondents answering 'no' or 'maybe' versus 'yes' to the question of whether they would be willing to switch from a single-drug regimen to multiple pills (once daily) for the treatment of HIV

\begin{tabular}{|c|c|c|c|c|}
\hline \multirow[t]{2}{*}{ Characteristic } & \multicolumn{2}{|l|}{ 'No’ vs. 'yes' } & \multicolumn{2}{|l|}{ 'Maybe’ vs. 'yes' } \\
\hline & $\begin{array}{l}\text { Univariate } \\
\text { OR }(95 \% \mathrm{CI})\end{array}$ & $\begin{array}{l}\text { Multivariate } \\
\text { OR }(95 \% \mathrm{CI})\end{array}$ & $\begin{array}{l}\text { Univariate } \\
\text { OR }(95 \% \mathrm{CI})\end{array}$ & $\begin{array}{l}\text { Multivariate } \\
\text { OR }(95 \% \mathrm{CI})\end{array}$ \\
\hline \multicolumn{5}{|l|}{ Age (years) } \\
\hline$<40$ & 1 & 1 & 1 & 1 \\
\hline $40-50$ & $0.67(0.31-1.46)$ & $1.05(0.45-2.45)$ & $1.08(0.45-2.63)$ & $1.56(0.59-4.11)$ \\
\hline $50-60$ & $0.29 * *(0.13-0.66)$ & $0.61(0.24-1.56)$ & $0.98(0.41-2.33)$ & $1.83(0.67-5.01)$ \\
\hline$\geq 60$ & $0.42 *(0.18-0.97)$ & $0.90(0.34-2.36)$ & $0.70(0.27-1.82)$ & $1.26(0.42-3.74)$ \\
\hline \multicolumn{5}{|c|}{ Sex and route of transmission } \\
\hline MSM & 1 & 1 & 1 & 1 \\
\hline Heterosexual, male & $1.77(0.72-4.33)$ & $1.60(0.60-4.25)$ & $1.97(0.80-4.85)$ & $1.66(0.62-4.47)$ \\
\hline Heterosexual, female & $2.47 *(1.08-5.68)$ & $1.90(0.74-4.91)$ & $2.96 *(1.30-6.75)$ & $2.54(1.00-6.47)$ \\
\hline Other & $2.12(0.59-7.61)$ & $1.52(0.37-6.24)$ & $2.84(0.83-9.71)$ & $2.16(0.54-8.61)$ \\
\hline \multicolumn{5}{|l|}{ Region of origin } \\
\hline The Netherlands & 1 & 1 & 1 & 1 \\
\hline Other & $2.98 * *(1.53-5.80)$ & $2.49 *(1.17-5.30)$ & $3.02 * *(1.54-5.91)$ & $2.63 *(1.24-5.60)$ \\
\hline \multicolumn{5}{|l|}{ Socioeconomic status } \\
\hline High & 1 & 1 & 1 & 1 \\
\hline Middle & $0.88(0.44-1.77)$ & $0.79(0.37-1.70)$ & $1.22(0.63-2.38)$ & $0.98(0.47-2.03)$ \\
\hline Low & $1.90(0.99-3.68)$ & $1.72(0.84-3.54)$ & $1.16(0.58-2.34)$ & $1.02(0.48-2.17)$ \\
\hline \multicolumn{5}{|c|}{ Time since cART initiation (years) } \\
\hline$<5$ & 1 & 1 & 1 & 1 \\
\hline $5-10$ & $0.67(0.34-1.34)$ & $0.59(0.28-1.22)$ & $0.84(0.40-1.79)$ & $0.81(0.37-1.79)$ \\
\hline $10-15$ & $0.88(0.41-1.91)$ & $0.98(0.42-2.30)$ & $1.75(0.80-3.86)$ & $1.59(0.67-3.81)$ \\
\hline$\geq 15$ & $0.23 * *(0.10-0.52)$ & $0.23 * *(0.09-0.58)$ & $0.52(0.23-1.16)$ & $0.42(0.17-1.02)$ \\
\hline \multicolumn{5}{|c|}{ Time since HIV diagnosis (years) ${ }^{\mathrm{a}}$} \\
\hline$<5$ & 1 & - & 1 & - \\
\hline $5-10$ & $1.40(0.58-3.42)$ & - & $0.77(0.31-1.92)$ & - \\
\hline $10-15$ & $1.30(0.51-3.31)$ & - & $1.27(0.51-3.16)$ & - \\
\hline$\geq 15$ & $0.40(0.15-1.08)$ & - & $0.59(0.24-1.47)$ & - \\
\hline
\end{tabular}

$c A R T$ combination antiretroviral therapy, MSM men who have sex with men

$* p<0.05, * * p<0.01, * * * p<0.001$

a Time since diagnosis was not included in the multivariate model because of collinearity (time since cART initiation)

three pills with the equivalent active ingredients simultaneously instead of one pill.

Our results show that patients' willingness to switch to MTR is to some extent dependent on how long they have been taking cART. Patients who had been taking cART $\geq 15$ years were more willing to take MTR, possibly because they experienced the years in which cART regimens were far more complex. Conversely, non-Dutch respondents were less willing to take MTR. A possible explanation for this could be that non-Dutch patients are more likely to have disclosure concerns, as reported in a previous study among HIV-infected patients in The Netherlands [17]. Patients preferring not to disclose their HIV-serostatus report more medication hiding [18, 19], and hiding medication may be perceived as easier with STR.

Our quantitative results show that patients (including respondents willing to switch) feel that switching to MTR is a step backwards. In addition, the most common concerns appear to be the dosing frequency, efficacy and tolerability of MTR. Thus, these matters deserve attention in both decision making and in informing the patient regarding MTR.

\subsection{Strengths and Limitations}

We consider the fact that we have data from all the treatment centres in the country to be a strength of this study. 
Furthermore, we offered the option of completing out a paper version of the questionnaire, to reduce sampling bias that can occur when collecting patient-reported data online [20]. Finally, the open-ended nature in which respondents could state their views and concerns provided us with a variety of information that we could not have anticipated had we chosen to offer a limited number of answers.

Despite efforts to recruit a nationally representative sample of individuals with HIV, patients from The Netherlands, MSM and patients with a higher SES were over-represented in our study sample, possibly resulting in a higher overall percentage of willingness to switch. Another limitation is the hypothetical character of our question (limited to 'once daily' dosage), with responses possibly not predictive for willingness in a real-life setting. In addition, given our aim to assess views in a cross-section of the HIV population, we posed the question to patients who were not on single-drug regimens at the time of participation. The response of those on STR (19\% willing to switch) and those on MTR (59\% willing to switch) may need to be interpreted differently. On the one hand, the individuals of concern in this matter (i.e. those on STR) have a strong preference for STR. On the other hand, one could argue that experience with multiple pills is not discouraging to the extent that, when given the (hypothetical) choice, patients would be reluctant to switch to MTR.

With regards to the generalizability of our results, it is important to bear in mind that in The Netherlands, where all citizens are legally required to be insured, there is universal access to cART (without co-payment). In settings where this is not the case, individual financial factors are likely to play to an important role in patients' positions regarding this matter.

\subsection{Implications}

This exploratory study shows that patients' preferences are not necessarily a reason to disregard the option of prescribing MTR. Our results suggest that, if well informed about the efficacy and tolerability, patients may find switching to MTR for economic reasons acceptable.

In particular, our results suggest that patients from The Netherlands and patients who have been taking cART for $\geq 15$ years (a substantial proportion of the HIV-infected population in The Netherlands) may be more likely to approve a switch to MTR. For patients more reluctant to switch, further inquiry into the concerns they may have is important. Our results suggest that these may include potency, tolerability, inconvenience and swallowing difficulties. Other issues to cover in clinical practice will differ per setting and include the financial consequences for the individual patient, the option to switch back to STR and dosing frequency.

\section{Conclusion}

HIV-infected patients do not necessarily oppose the decision to prescribe MTR instead of STR to reduce healthcare costs. However, the potential trade-off in terms of convenience should be carefully weighed against the projected savings. Moreover, considering the scarcity of evidence on the efficacy and safety of switching to MTR [3, 13], outcomes of such switches should be closely monitored over the long term.

Acknowledgements Preliminary results were previously presented at the HIV Drug Therapy Glasgow Congress 2014 [21].

We thank all study participants for their contribution, and the physicians and nursing consultants who made the collection of the data possible.

Clinical Centres (collaborating with the ATHENA observational cohort): *Denotes site coordinating physician

Academic Medical Centre of the University of Amsterdam: HIV treating physicians: J.M. Prins*, T.W. Kuijpers, H.J. Scherpbier, J.T.M. van der Meer, F.W.M.N. Wit, M.H. Godfried, P. Reiss, T. van der Poll, F.J.B. Nellen, S.E. Geerlings, M. van Vugt, D. Pajkrt, J.C. Bos, W.J. Wiersinga, M. van der Valk, A. Goorhuis, J.W. Hovius. HIV nurse consultants: J. van Eden, A. Henderiks, A.M.H. van Hes, M. Mutschelknauss, H.E. Nobel, F.J.J. Pijnappel. HIV clinical virologists/chemists: S. Jurriaans, N.K.T. Back, H.L. Zaaijer, B. Berkhout, M.T.E. Cornelissen, C.J. Schinkel, X.V. Thomas. Admiraal De Ruyter Ziekenhuis, Goes: HIV treating physicians: M. van den Berge, A. Stegeman. HIV nurse consultants: S. Baas, L. Hage de Looff. HIV clinical virologists/chemists: D. Versteeg. Catharina Ziekenhuis, Eindhoven: HIV treating physicians: M.J.H. Pronk*, H.S.M. Ammerlaan. HIV nurse consultants: E.S. de Munnik, E. van Beek. HIV clinical virologists/chemists: A.R. Jansz, J. Tjhie, M.C.A. Wegdam, B. Deiman, V. Scharnhorst. Emma Kinderziekenhuis: HIV nurse consultants: A. van der Plas, A.M. Weijsenfeld. Erasmus MC, Rotterdam: HIV treating physicians: M.E. van der Ende*, T.E.M.S. de Vries-Sluijs, E.C.M. van Gorp, C.A.M. Schurink, J.L. Nouwen, A. Verbon, B.J.A. Rijnders, H.I. Bax, M. van der Feltz. HIV nurse consultants: N. Bassant, J.E.A. van Beek, M. Vriesde, L.M. van Zonneveld. Data collection: A. de Oude-Lubbers, H.J. van den BergCameron, F.B. Bruinsma-Broekman, J. de Groot, M. de Zeeuw- de Man. HIV clinical virologists/chemists: C.A.B. Boucher, M.P.G Koopmans, J.J.A van Kampen, S.D. Pas. Erasmus MC-Sophia, Rotterdam: HIV treating physicians: G.J.A. Driessen, A.M.C. van Rossum. HIV nurse consultants: L.C. van der Knaap, E. Visser. Flevoziekenhuis, Almere: HIV treating physicians: J. Branger*, A. Rijkeboer-Mes. HIV nurse consultant and data collection: C.J.H.M. Duijf-van de Ven. HagaZiekenhuis, Den Haag: HIV treating physicians: E.F. Schippers*, C. van Nieuwkoop. HIV nurse consultants: J.M. van IJperen, J. Geilings. Data collection: G. van der Hut. HIV clinical virologist/chemist: P.F.H. Franck. HIV Focus Centrum (DC Klinieken): HIV treating physicians: A. van Eeden*. HIV nurse consultants: W. Brokking, M. Groot, L.J.M. Elsenburg. HIV clinical virologists/chemists: M. Damen, I.S. Kwa. Isala, Zwolle: HIV treating physicians: P.H.P. Groeneveld*, J.W. Bouwhuis. HIV nurse consultants: J.F. van den Berg, A.G.W. van Hulzen. Data collection: G.L. van der Bliek, P.C.J. Bor. HIV clinical virologists/chemists: P. Bloembergen, M.J.H.M. Wolfhagen, G.J.H.M. Ruijs. Leids Universitair Medisch Centrum, Leiden: HIV treating physicians: F.P. Kroon*, M.G.J. de Boer, M.P. Bauer, H. Jolink, A.M. Vollaard. HIV nurse consultants: W. Dorama, N. van Holten. HIV clinical virologists/chemists: E.C.J. Claas, E. Wessels. Maasstad Ziekenhuis, Rotterdam: HIV treating physicians: J.G. den Hollander*, K. 
Pogany, A. Roukens. HIV nurse consultants: M. Kastelijns, J.V. Smit, E. Smit, D. Struik-Kalkman, C. Tearno. Data collection: M. Bezemer, T. van Niekerk. HIV clinical virologists/chemists: O. Pontesilli. Maastricht UMC + , Maastricht: HIV treating physicians: S.H. Lowe*, A.M.L. Oude Lashof, D. Posthouwer. HIV nurse consultants: R.P. Ackens, J. Schippers, R. Vergoossen. Data collection: B. Weijenberg-Maes. HIV clinical virologists/chemists: I.H.M. van Loo, T.R.A. Havenith. MCH-Bronovo, Den Haag: HIV treating physicians: E.M.S. Leyten*, L.B.S. Gelinck. HIV nurse consultants: A. van Hartingsveld, C. Meerkerk, G.S. Wildenbeest. HIV clinical virologists/chemists: J.A.E.M. Mutsaers, C.L. Jansen. MC Slotervaart, Amsterdam: HIV treating physicians: J.W. Mulder, S.M.E. Vrouenraets, F.N. Lauw. HIV nurse consultants: M.C. van Broekhuizen, H. Paap, D.J. Vlasblom. HIV clinical virologists/chemists: P.H.M. Smits. MC Zuiderzee, Lelystad: HIV treating physicians: S. Weijer*, R. El Moussaoui. HIV nurse consultant: A.S. Bosma. Medisch Centrum Leeuwarden, Leeuwarden: HIV treating physicians: M.G.A.van Vonderen*, D.P.F. van Houte, L.M. Kampschreur. HIV nurse consultants: K. Dijkstra, S. Faber. HIV clinical virologists/chemists: J Weel. Medisch Spectrum Twente, Enschede: HIV treating physicians: G.J. Kootstra*, C.E. Delsing. HIV nurse consultants: M. van der Burg-van de Plas, H. Heins. Data collection: E. Lucas. Noordwest Ziekenhuisgroep, Alkmaar: HIV treating physicians: W. Kortmann*, G. van Twillert*, J.W.T. Cohen Stuart, B.M.W. Diederen. HIV nurse consultant and data collection: D. Pronk, F.A. van Truijen-Oud. HIV clinical virologists/chemists: W. A. van der Reijden, R. Jansen. OLVG, Amsterdam: HIV treating physicians: K. Brinkman*, G.E.L. van den Berk, W.L. Blok, P.H.J. Frissen, K.D. Lettinga W.E.M. Schouten, J. Veenstra. HIV nurse consultants: C.J. Brouwer, G.F. Geerders, K. Hoeksema, M.J. Kleene, I.B. van der Meché, M. Spelbrink, H. Sulman, A.J.M. Toonen, S. Wijnands. HIV clinical virologists: M. Damen, D. Kwa. Data collection: E. Witte. Radboudumc, Nijmegen: HIV treating physicians: R. van Crevel*, P.P. Koopmans, M. Keuter, A.J.A.M. van der Ven, H.J.M. ter Hofstede, A.S.M. Dofferhoff. HIV nurse consultants: M. Albers, M.E.W. Bosch, K.J.T. Grintjes-Huisman, B.J. Zomer. HIV clinical virologists/chemists: F.F. Stelma, J. Rahamat-Langendoen. HIV clinical pharmacology consultant: D. Burger. Rijnstate, Arnhem: HIV treating physicians: C. Richter*, E.H. Gisolf, R.J. Hassing. HIV nurse consultants: G. ter Beest, P.H.M. van Bentum, N. Langebeek. HIV clinical virologists/chemists: R. Tiemessen, C.M.A. Swanink. Spaarne Gasthuis, Haarlem: HIV treating physicians: S.F.L. van Lelyveld*, R. Soetekouw. HIV nurse consultants: N. Hulshoff, L.M.M. van der Prijt, J. van der Swaluw. Data collection: N. Bermon. HIV clinical virologists/chemists: W.A. van der Reijden, R. Jansen, B.L. Herpers, D.Veenendaal. Medisch Centrum Jan van Goyen, Amsterdam: HIV treating physicians: D.W.M. Verhagen. HIV nurse consultants: M. van Wijk. St Elisabeth Ziekenhuis, Tilburg: HIV treating physicians: M.E.E. van Kasteren*, A.E. Brouwer. HIV nurse consultants and data collection: B.A.F.M. de Kruijf-van de Wiel, M. Kuipers, R.M.W.J. Santegoets, B. van der Ven. HIV clinical virologists/chemists: J.H. Marcelis, A.G.M. Buiting, P.J. Kabel. Universitair Medisch Centrum Groningen, Groningen: $H I V$ treating physicians: W.F.W. Bierman*, H. Scholvinck, K.R. Wilting, Y. Stienstra. HIV nurse consultants: H. de Groot-de Jonge, P.A. van der Meulen, D.A. de Weerd, J. Ludwig-Roukema. HIV clinical virologists/chemists: H.G.M. Niesters, A. Riezebos-Brilman, C.C. van Leer-Buter, M. Knoester. Universitair Medisch Centrum Utrecht, Utrecht: HIV treating physicians: A.I.M. Hoepelman*, T. Mudrikova, P.M. Ellerbroek, J.J. Oosterheert, J.E. Arends, R.E. Barth, M.W.M. Wassenberg, E.M. Schadd. HIV nurse consultants: D.H.M. van Elst-Laurijssen, E.E.B. van Oers-Hazelzet, S. Vervoort, Data collection: M. van Berkel. HIV clinical virologists/chemists: R. Schuurman, F. Verduyn-Lunel, A.M.J. Wensing. VUmc, Amsterdam: HIV treating physicians: E.J.G. Peters*, M.A. van Agtmael, M. Bomers, J. de Vocht. HIV nurse consultants: M. Heitmuller, L.M.
Laan. HIV clinical virologists/chemists: A.M. Pettersson, C.M.J.E. Vandenbroucke-Grauls, C.W. Ang. Wilhelmina Kinderziekenhuis, UMCU, Utrecht: HIV treating physicians: S.P.M. Geelen, T.F.W. Wolfs, L.J. Bont. HIV nurse consultants: N. Nauta.

\section{Compliance with Ethical Standards}

Ethical Approval This study was exempted from written informed consent (by the Medical Ethics Review Committee of the Academic Medical Centre of the University of Amsterdam). All patients were informed about the study and we considered consent implicit when a survey was returned to us. Patients who had opted out of registration in the ATHENA cohort were not included.

Conflict of interest SCJMV has received travel grants from Abbvie and Gilead. PJS through his institution has received grants from (the former) Abbott Laboratories and Gilead Sciences. PR through his institution has received independent scientific grant support from Gilead Sciences, Janssen Pharmaceuticals Inc, Merck \& Co, BristolMyers Squibb and ViiV Healthcare; he has served on a scientific advisory board for Gilead Sciences; he serves on a data safety monitoring committee for Janssen Pharmaceuticals Inc; and chaired a scientific symposium by ViiV Healthcare, for which his institution has received remuneration. KB serves on advisory boards for MSD, Gilead, BMS, Viiv and Janssen, for which he has received remuneration. The authors EANE, CS, PTN, FPK and SEG declare that they have no conflicts of interest.

Funding This research was supported by Aids Fonds (grant number: 2011015). The ATHENA database is maintained by Stichting HIV Monitoring and supported by a grant from the Dutch Ministry of Health, Welfare, and Sport through the Centre for Infectious Disease Control of the National Institute for Public Health and the Environment.

Coordinating Centre Director: P. Reiss. Data analysis: D.O. Bezemer, A.I. van Sighem, C. Smit, F.W.M.N. Wit, T.S. Boender. Data management and quality control: S. Zaheri, M. Hillebregt, A. de Jong. Data monitoring: D. Bergsma, P. Hoekstra, A. de Lang, S. Grivell, A. Jansen, M.J. Rademaker, M. Raethke, R. Meijering, S. Schnörr. Data collection: L. de Groot, M. van den Akker, Y. Bakker, E. Claessen, A. El Berkaoui, J. Koops, E. Kruijne, C. Lodewijk, L. Munjishvili, B. Peeck, C. Ree, R. Regtop, Y. Ruijs, T. Rutkens, L. van de Sande, M. Schoorl, A. Timmerman, E. Tuijn, L. Veenenberg, S. van der Vliet, A. Wisse, T. Woudstra. Patient registration: B. Tuk.

Open Access This article is distributed under the terms of the Creative Commons Attribution-NonCommercial 4.0 International License (http://creativecommons.org/licenses/by-nc/4.0/), which permits any noncommercial use, distribution, and reproduction in any medium, provided you give appropriate credit to the original author(s) and the source, provide a link to the Creative Commons license, and indicate if changes were made.

\section{References}

1. Blanco JL, Montaner JS, Marconi VC, et al. Lower prevalence of drug resistance mutations at first-line virological failure to firstline therapy with atripla vs. tenofovir + emtricitabine/lamivudine + efavirenz administered on a multiple tablet therapy. Aids. 2014;28(17):2531-9.

2. Gandhi M, Gandhi RT. Single-pill combination regimens for treatment of HIV-1 infection. N Engl J Med. 2014;371(3): 248-59. 
3. Engsig FN, Gerstoft J, Helleberg M, et al. Effectiveness of antiretroviral therapy in individuals who for economic reasons were switched from a once-daily single-tablet regimen to a tripletablet regimen. J Acquir Immune Defic Syndr (1999). 2014;66(4):407-13.

4. Walensky RP, Sax PE, Nakamura YM, et al. Economic savings versus health losses: the cost-effectiveness of generic antiretroviral therapy in the United States. Ann Intern Med. 2013;158(2): 84-92.

5. Hill A, Hill T, Jose S, Pozniak A. Predicted savings to the UK National Health Service from switching to generic antiretrovirals, 2014-2018. J Int AIDS Soc. 2014;17(4 Suppl 3):19497.

6. van Galen KA, Nellen JF, Nieuwkerk PT. The effect on treatment adherence of administering drugs as fixed-dose combinations versus as separate pills: systematic review and meta-analysis. AIDS Res Treat. 2014;2014:967073.

7. Parienti JJ, Bangsberg DR, Verdon R, Gardner EM. Better adherence with once-daily antiretroviral regimens: a meta-analysis. Clin Infect Dis. 2009;48(4):484-8.

8. Gianotti N, Galli L, Bocchiola B, et al. Number of daily pills, dosing schedule, self-reported adherence and health status in 2010: a large cross-sectional study of HIV-infected patients on antiretroviral therapy. HIV Med. 2013;14(3):153-60.

9. Langebeek N, Gisolf EH, Reiss P, et al. Predictors and correlates of adherence to combination antiretroviral therapy (ART) for chronic HIV infection: a meta-analysis. BMC Med. 2014;12:142.

10. Hill A, Pozniak A, Simmons B. No difference in risk of virological failure between antiretroviral treatments using co-formulated versus individual drugs: Meta-analysis of 9 randomised trials in 2,568 patients; Abstracts of the 21st Annual Conference of the British HIV Association (BHIVA), Brighton, UK, 21-24 April 2015. HIV Med. 2015;16(Suppl 2):1-77.

11. Ilozue C, Parirenyatwa R, Parris V, Chadwick D. Experience of switching patients from Atripla to Truvada and generic efavirenz in a medium-sized HIV clinic: Patient attitudes, safety and cost savings; Abstracts of the 21st Annual Conference of the British HIV Association (BHIVA), Brighton, UK, 21-24 April 2015. HIV Med. 2015;16(Suppl 2):1-77.

12. Saxon C, Ahmad S. Experience of switching from Atripla to generic efavirenz at a metropolitan HIV clinic: outcome and cost analysis; Abstracts of the 21st Annual Conference of the British HIV Association (BHIVA), Brighton, UK, 21-24 April 2015. HIV Med. 2015;16(Suppl 2):1-77.

13. Nachega JB, Parienti JJ, Uthman OA, et al. Lower pill burden and once-daily antiretroviral treatment regimens for HIV infection: A meta-analysis of randomized controlled trials. Clin Infect Dis. 2014;58(9):1297-307.

14. Buscher A, Hartman C, Kallen MA, Giordano TP. Impact of antiretroviral dosing frequency and pill burden on adherence among newly diagnosed, antiretroviral-naive HIV patients. Int $\mathbf{J}$ STD AIDS. 2012;23(5):351-5.

15. van Sighem A GL, Smit C, Stolte I, Reiss P. Human immunodeficiency virus (HIV) infection in the Netherlands. Monitoring report 2014. http://www.hiv-monitoring.n1/files/8914/1527/1076/ SHM_Monitoring_report_2014.pdf2014.

16. The Netherlands institute for social research. http://www.scp. nl/english/Publications/Summaries_by_year/Summaries_2012/ Neighbourhood_status_development_in_the_Netherlands_1998_ 20102012.

17. Sumari-de Boer IM, Nellen JFB, Sprangers MAG, Prins JM, Nieuwkerk PT. Personalized stigma and disclosure concerns among HIV-infected immigrant and indigenous hiv-infected persons in the Netherlands. J HIV/AIDS Soc Serv. 2012;11(1): $42-56$.

18. Rao D, Kekwaletswe TC, Hosek S, Martinez J, Rodriguez F. Stigma and social barriers to medication adherence with urban youth living with HIV. AIDS Care. 2007;19(1):28-33.

19. Calabrese SK, Martin S, Wolters PL, Toledo-Tamula MA, Brennan TL, Wood LV. Diagnosis disclosure, medication hiding, and medical functioning among perinatally infected. HIV-positive children and adolescents. AIDS Care. 2012;24(9):1092-6.

20. Jenkins PJ, Sng S, Brooksbank K, Brooksbank AJ. Socioeconomic deprivation and age are barriers to the online collection of patient reported outcome measures in orthopaedic patients. Ann R Coll Surg Engl. 2016;98(1):40-4.

21. Engelhard E, Smith C, Vervoort S, Kroon F, Brinkman K, Nieuwkerk P, et al. Patients' willingness to take separate component antiretroviral therapy regimens for HIV in The Netherlands. J Int AIDS Soc. 2014;17(4 Suppl 3):19536 